\title{
Experimental Analysis of Bamboo and E-Glass Fiber Reinforced Epoxy Hybrid Composite
}

\author{
Daniel Redda ${ }^{*}$ and Abiy Alene \\ School of Mechanical and Industrial Engineering, Addis Ababa University, King George VI Street -385, Ethiopia
}

\begin{abstract}
The main objective of this research is to investigate the performance of bamboo and E-glass fiber reinforced epoxy hybrid composite (BEGRC) for various applications. Initially, manual bamboo fiber extraction method was applied on Ethiopian highland bamboo species "Yushania Alpina" and soaked in a 5\% $\mathrm{NaOH}$ to remove lignin and hemicellulose from fibers. Next, the bamboo and E-glass fiber test specimen was fabricated with $45 \%$ total fiber volume fraction and tensile, compressive, in-plane shear and flexural tests were carried out using universal testing machine. In the case of bamboo to E-glass fiber ratio of $50: 50$, it has high elastic modulus and better compressive strength. Therefore, it is clear that that bamboo and E-glass reinforced epoxy hybrid composite can be applied to various systems that require light weight and high strength.
\end{abstract}

Key words: Bamboo, E-glass fiber, epoxy, hybrid composite, alkaline.

\section{Introduction}

Most of modern industrial artifacts such as wind turbine blades, aircraft, ship and automotive parts are manufactured from massive amount of synthetic fibers. However these synthetic fibers have many drawbacks from the fact that non-recyclable, environmental pollution and high costs. From this aspect, attention has given to materials such as vegetable fibers including jute, wastes from industry, mining and agricultural products for engineering applications to control environmental degradation and to minimize cost $[1,2]$.

Natural fibers have been popular reinforcement material for fiber reinforced polymer composite developments. These reinforcement can replace the conventional fiber, such as glass as an alternative material. Other than these natural fibers, bamboo is another interesting material considered as plant fiber $\&$ has a great potential to be used in polymer composite industry [3-6]. According to Ref. [4-8], it is known that bamboo is one of the ecological materials

*Corresponding author: Daniel Tilahun Redda, Ph.D., research fields: mechanical design, tribology and materials engineering. for which it has many distinct characteristics: it reaches its maximum strength in just few years, it is renewable material and have simple production process, have fairly good mechanical properties with high specific strength, non-abrasive, eco-friendly and bio-degradability characteristics, have low cost and weight $[8,9]$. This study has two parts. The first part of the study focused on bamboo fiber extraction from bamboo culm and fiber treatment. The second part focused on experimental investigation of tensile, compressive, flexural and in-plane shear strength of bamboo and E-glass-fiber reinforced epoxy hybrid composite.

\section{Materials}

In this work, System \#2000 epoxy resin and System \#2060 hardener (Fiber Glast Development Corporation, USA) were used. The bamboo fibers is extracted in this work from Ethiopian highland bamboo (Yushania Alpina) collected from Injibara, North West part of Ethiopia, in green form. A UD E-glass fibers were used for bamboo fibers reinforcement, which is obtained from Dejen Aviation (Davi), Bishoftu, Ethiopia. 


\subsection{Bamboo Fiber Extraction}

There is After nodes, most inner parts and outer thin layer of exoderm of the highland bamboo have been removed, the remaining parts have cleaved in longitudinal direction to thin strips using band saw. Then these strips are bundled and kept in water for five days in order to soften them. After removing, they are beaten gently at slow constant impact load using rubber hammer in order to loosen and separate the fiber (Fig. 1a). The resulting fiber bundle is combed using wire comb. (Fig. 1b). Next these fibers were soaked in $5 \% \mathrm{NaOH}$ solution for 24 hours at $60^{\circ} \mathrm{C}$ in the in oven dry to remove excess fats from individual fiber (Fig. 1c).

Finally the fibers washed many times in distilled water, and dried under the sun for four weeks. At the end, fibers with a diameter of 170-300 $\mu \mathrm{m}$ and length of 0.35-0.4 m were selected as hybrid reinforcement.
Finally these fibers were prepared manually in unidirectional manner (Fig. 1d).

\subsection{Preparation of Test Specimen}

The BGREC is prepared on the $1,500 \mathrm{~mm} \times 500$ $\mathrm{mm} \times 2 \mathrm{~mm}$ size of aluminum plate as a mold. The plate mold was first coated with polyvinyl alcohol solution (PVA) and then coated three times with thin layer of paste wax to easily release composite from mold. BEGRC specimen was fabricated with $45 \%$ fiber volume fraction using vacuum bagging assisted hand lay-up technique (Fig. 2). Impregnation process is carried out manually (Fig. 3a).

A $[0 / 90 / 0 / \underline{90}]_{\mathrm{s}}$ laminae orientation was used to produce $2.5 \mathrm{~mm}$ composite plate thickness for tensile testing. Compressive and bending test specimens were prepared as $\left[90_{2} / 0_{2} /-45 / 45\right]_{\mathrm{s}}$ laminae orientation according to ASTM standard that gave $4 \mathrm{~mm}$ thick

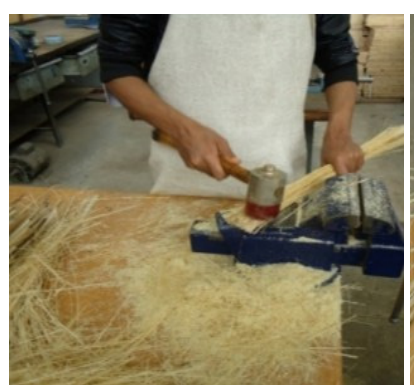

(a)

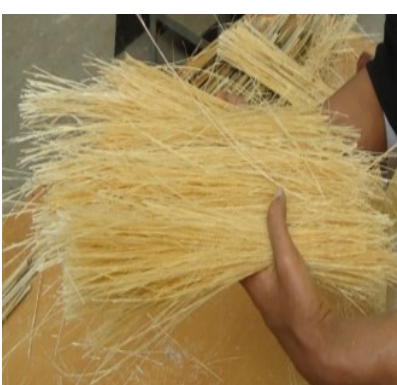

(b)

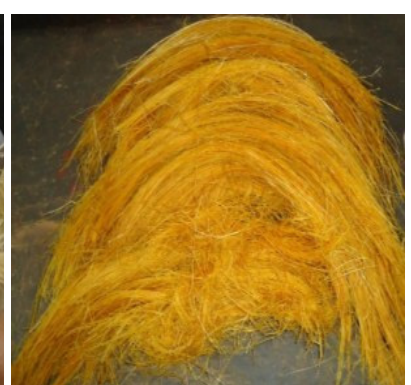

(c)

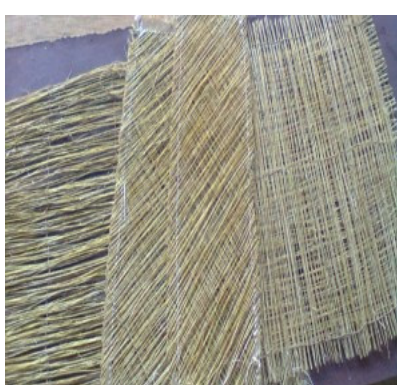

(d)

Fig. 1 Bamboo fiber extraction process.

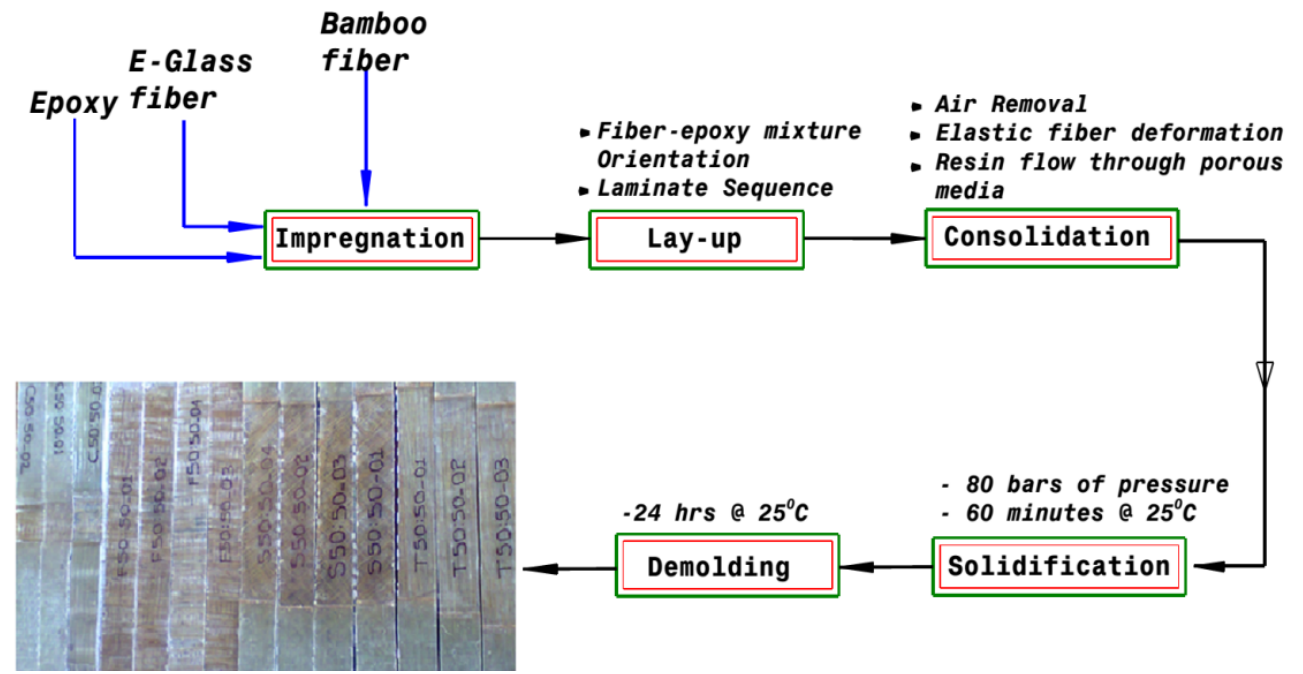

Fig. 2 Flowchart of fabrication process of laminated composite using VBAHT. 

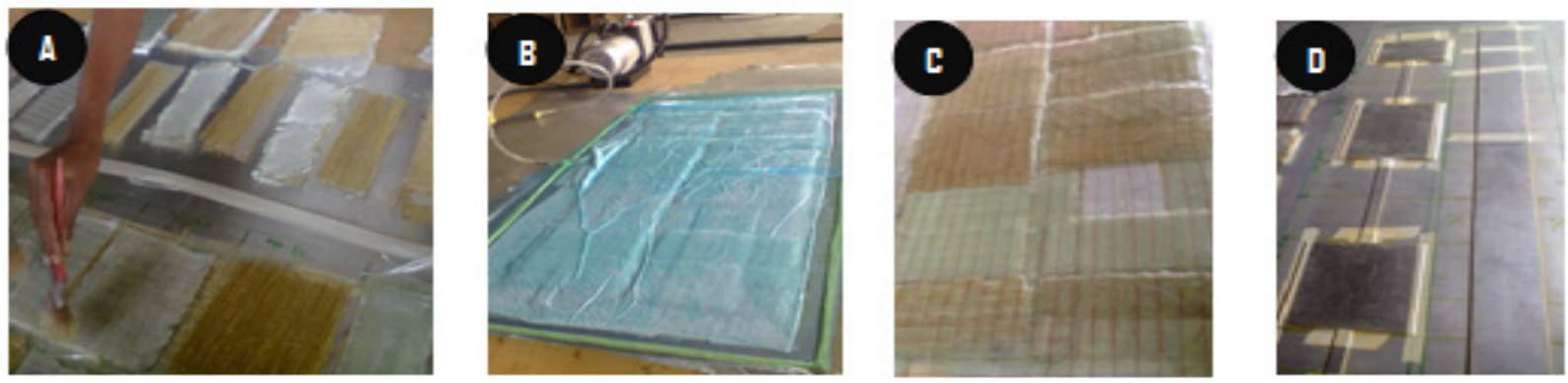

Fig. 3 Composite fabrication by vacuum bagging system: (a) impregnation \& lay-up, (b) consolidation, (c) curved BEGRC and ( d) aluminum mold.

composite plate. Similarly In-Plane Shear coupon was prepared by off-axis tensile tests of $\mathrm{a} \pm 45^{\circ}\left(+45^{\circ}\right.$ and $-45^{\circ}$ lamina) orientation and produce $2.5 \mathrm{~mm}$ thick composite plate.

Then in consolidation stage, vacuum bagging materials are applied to draw excess air (Fig. 3b). Next solidification stage is processed at 80 bars of pressure and $25^{\circ} \mathrm{C}$ with in $2 \mathrm{hrs}$. Finally it dried for 24 hrs. at room temperature. A $[0 / 90 / 0 / 90]_{s}$ laminae orientation were used to produce $2.5 \mathrm{~mm}$ composite plate thickness for tensile testing. Compressive and bending test specimens were prepared as $\left[90_{2} / 0_{2} /-45 / 45\right]_{\mathrm{s}}$ laminae orientation according to ASTM standard that gave $4 \mathrm{~mm}$ thick composite plate.

Similarly In-Plane Shear coupon was prepared by off-axis tensile tests of $\mathrm{a} \pm 45^{\circ}\left(+45^{\circ}\right.$ and $-45^{\circ}$ lamina) orientation and produce $2.5 \mathrm{~mm}$ thick composite plate. Middle plane was used in order to separate the composite in to two half thickness of laminate symmetrically as well as in order to keep the balance of the stack. This assists the composite not easily to delaminate during the loading. Generally, 9 laminae for tensile, 15 laminae for shear, 14 laminae for compressive $\&$ bending test specimens are used.

\section{Results and Discussion}

\subsection{Results}

Tensile tests, in-plane shearing test compressive tests and bending tests were performed with Universal Testing Machine (UTM) with cross head speed of 2, 2, 3 and $5 \mathrm{~mm} / \mathrm{min}$ respectively.

Typical stress-strain curves for BEGRC under tensile loading, in-plane shear loading, compression loading and three point bending load is presented in Figs. $4 \mathrm{a}, 4 \mathrm{~b}, 4 \mathrm{c}$ and $4 \mathrm{~d}$, respectively.

\subsection{Discussion}

\subsubsection{Tensile Test}

From Fig. 4a, tensile stress increased linearly with increase in strain until point of ultimate load under tensile loading. Above this point, the stress-strain curve showed sharp, staggered decreases in load and fracture. Laminate under a tensile loading, a kink is observed in few specimens in the graph indicating the BEGRC load and the curve continues with increasing load, but with a smaller slope, signifying a reduced stiffness in the direction of the load. Tensile fracture of unidirectional is mainly longitudinal cracking of fibers.

The minimum ultimate strength is $187.73 \mathrm{MPa}$ for bamboo alone composite and the maximum value is 557.29 MPa for E-glass alone composite (Fig. 5). In general, we concluded that as increase of bamboo fiber percentages, the tensile strength decreases slightly.

\subsubsection{In-Plane Shearing Test}

The typical stress-strain curves for BGREC under in-plane shearing load and ultimate stress with percentage of bamboo \& E-glass fiber ratio was presented in Fig. 4b. This graph showed that shear stress increased linearly with increase in strain until point of ultimate load under shearing load. Above this point, the stress-strain curve showed a slow decrement in load and failure happened at ultimate 


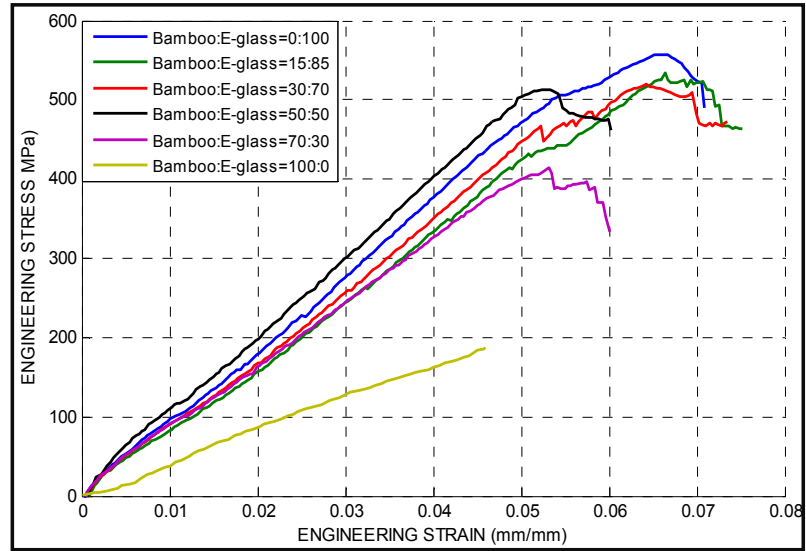

(a)

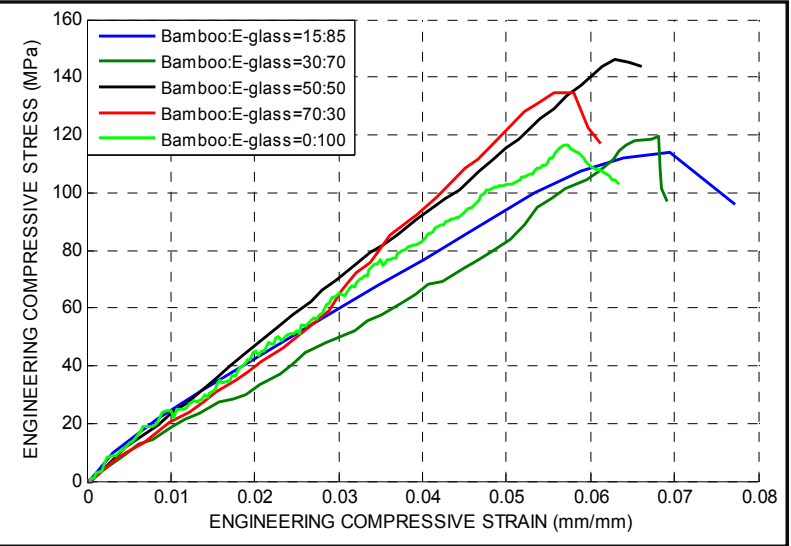

(c)

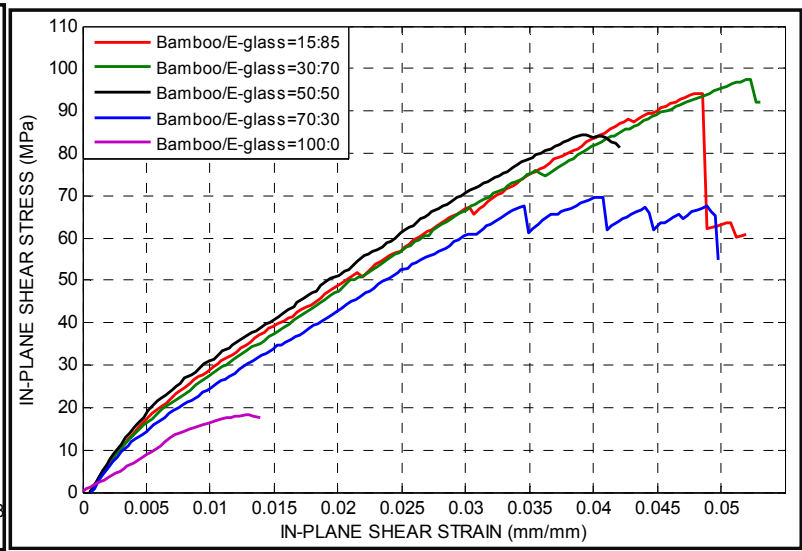

(b)

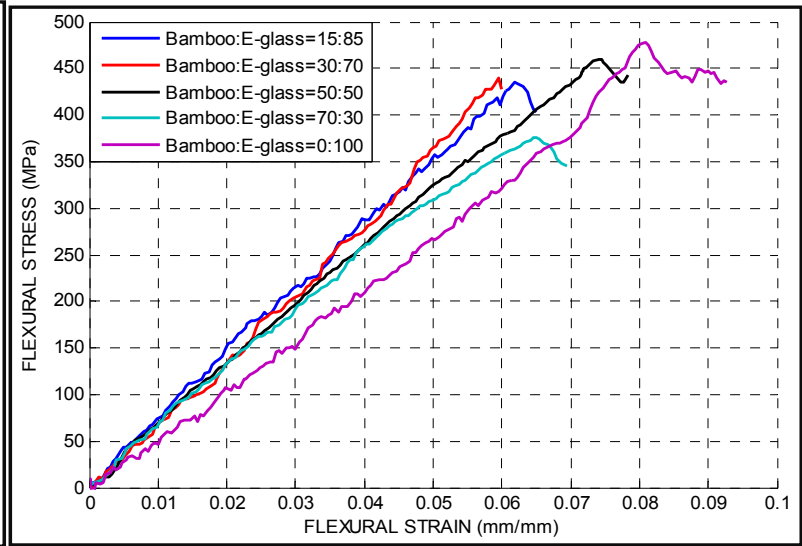

(d)

Fig. 4 Stress vs Strain curve for (a) tensile, (b) in-plane, (c) compressive and (d) flexural loading.

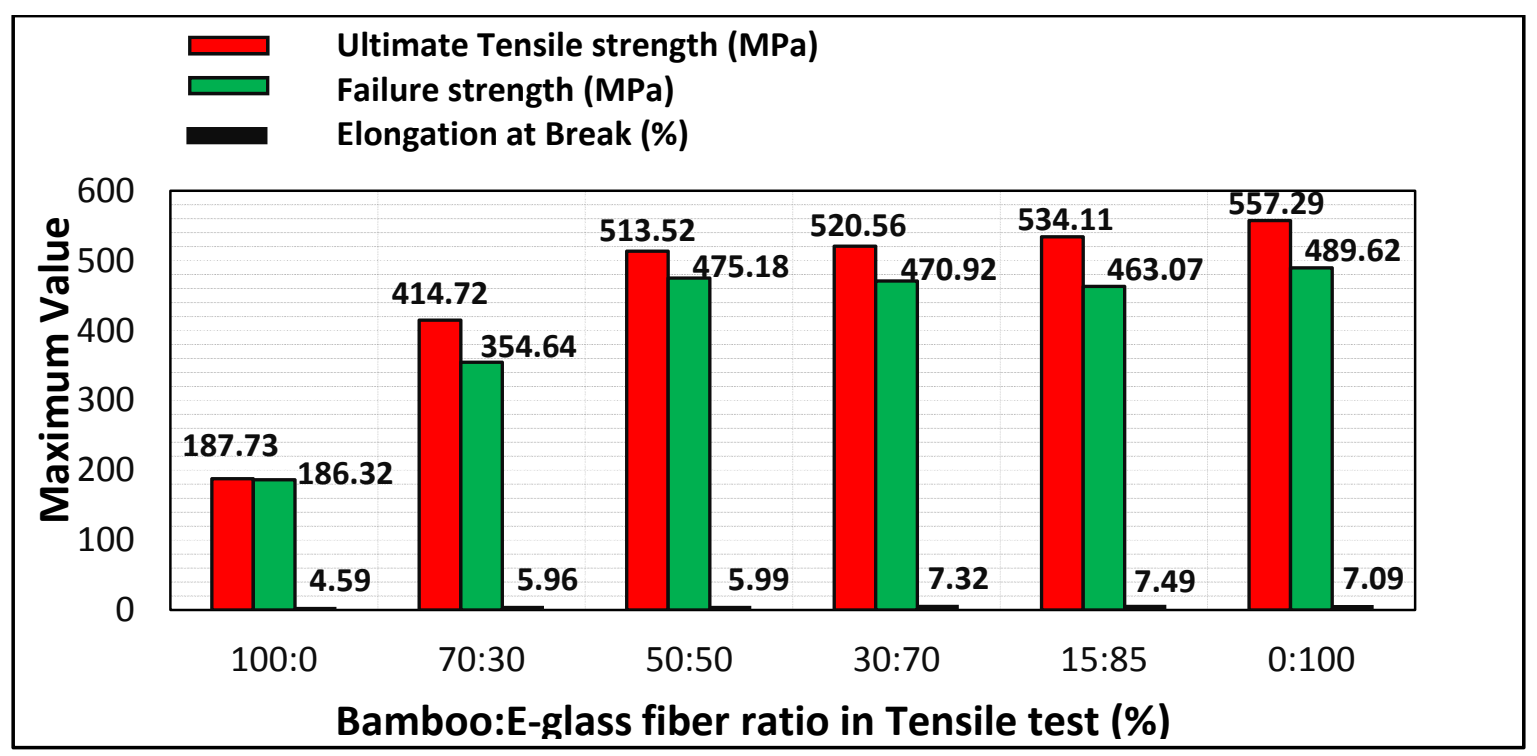

Fig. 5 Comparison of different bamboo/ E-glass ratio tensile peak value.

failure point. The minimum shear strength is 18.18 MPa for bamboo alone composite and the maximum value is $97.55 \mathrm{MPa}$ for $30: 70$ ratio (Fig. 6).

\subsubsection{Compressive Test}

Fig. 4c indicated that compressive stress increased with an increment of strain until point of ultimate 
stress under compressive loading. Above this point, the stress-strain curve showed non-linear segments. This graph shown that the increment value is non-linear, in which the responsible for this response is jerky/stick-slip behavior. During fracture, compressive stress of BEGRCs rapidly decreased with buckling of specimens.

According to the Tsai-Hill criteria [7], the properties of composites continuously decrease as the angle of orientation of the fibers increases from $0^{\circ}$. In this study, fibers direction in all laminae are same i.e. unidirectional, but ply angles are different in all type of BEGRCs samples. So, due to an increment in numbers of layers and orientation of middle layers fibers from $0^{\circ}$, the compressive strength obtained is much lower than the tensile strength which are all fibers of laminate are in unidirectional way.

Fig. 7 illustrated the peak values of compressive strength, failure strength, failure strain and (0.2\%) yield strength. Ratio of 50 : 50 recorded a higher compressive- strength, 146.22 $\mathrm{MPa}$; And a minimum value is obtained from the $15: 85$ ratio, which is 114.13 $\mathrm{MPa}$.

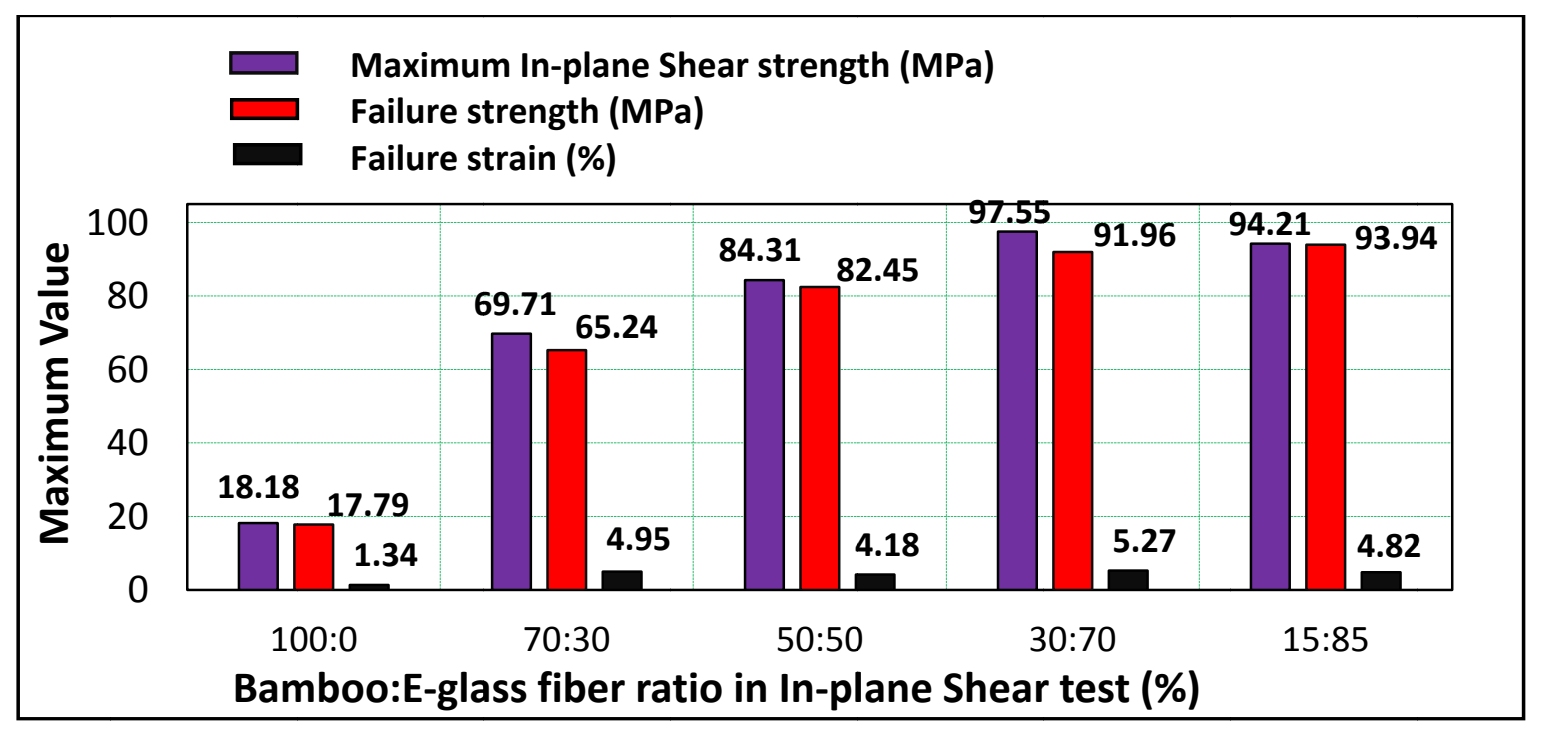

Fig. 6 Comparison of different bamboo/E-glass ratio in-plane shear peak value.

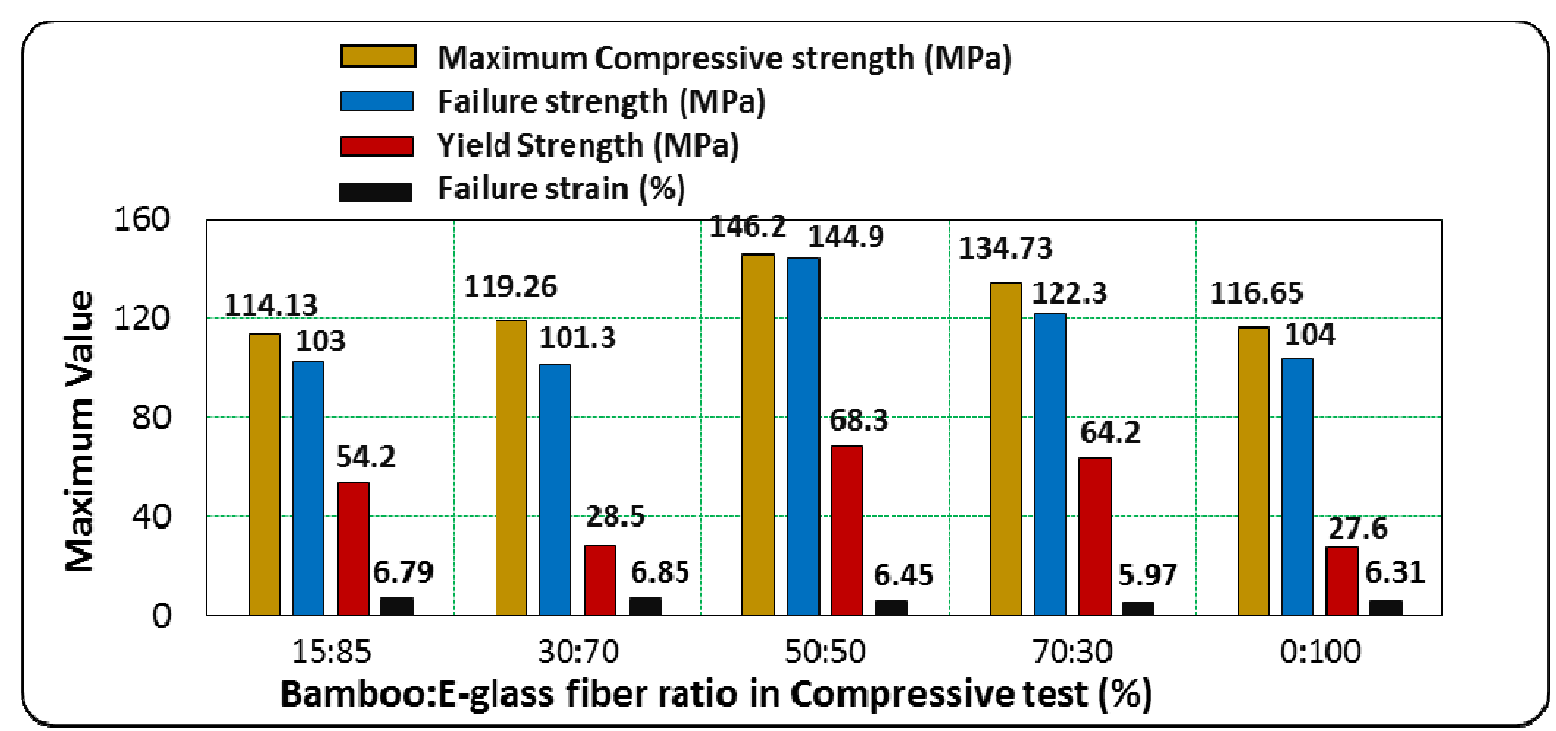

Fig. 7 Comparison of different bamboo/E-glass ratio compressive peak value. 


\subsubsection{Flexural Test}

From Fig. 4d flexural stress increased linearly with increase in strain until point of maximum flexure stress under bending load. Above this point, the stress-strain curve showed non-linear segments. The peak value of flexure rupture, failure strength and failure strain of each BGREC ratio in bending load is clearly illustrated in figure 8 . Here, bending fractures concentrated near the middle of the test specimen where load was applied. The minimum flexural strength is $376.17 \mathrm{MPa}$ for $70: 30$ composite and the maximum value is $478.35 \mathrm{MPa}$ for $0: 100$ composite. Bamboo, E-glass \& epoxy bond revealed a strong fluctuations of stress-strain curve (slip-stick effect) recorded during uniaxial compression and bending tests.

The load oscillations happened due to the stick-slip. Responsible for this stick-slip is due to small strain rates and small specimens with slow loading rates used during UTM test [10].

Modulus of elasticity for tensile, shear, compressive and flexural tests also determined, as illustrated in Fig. 9. The minimum and maximum values of tensile modulus for these composites are found to be 3211 and 11,588 MPa respectively.

As we observe from the graph, a good tensile modulus is recorded in a $50: 50$ ratio of bamboo to
E-glass fiber ratio. Shear modulus of elasticity also determined, and 3,568 MPa for $100: 0$ and 5,418 MPa for $50: 50$ ratios were a minimum and maximum values. As well the compressive moduli of these composites vary between 1,906 and 2,630 MPa.

Similarly, the flexural modulus also vary between 5,047.7 and 7,681.26 MPa. This observation clearly indicates that the BEGRC with $50: 50$ bamboo to E-glass ratio has relatively higher moduli in almost all the tests carried out. As a result, this ratio has a better load-bearing capacity.

\subsubsection{Failure Modes Identification}

Fig. 10 and Table 1 show the mode of failures of the specimens. All specimens under tensile loading exhibited similar failure modes; that is explosive failure types at the middle of gage area. In the case of $100: 0$ ratio, types of failure identified are lateral failure types.

It also observed that some specimens start to fail at grips \& multimode types. For all layers of laminate, first matrix (adhesive between fibers) failure occurs followed by fibers failure through then fracture propagates spontaneously. Compressive failure was attributed by micro buckling surrounded by delamination. The delaminated portions spread to the intact areas of the laminate by a combination of delamination buckling and growth, the buckling further

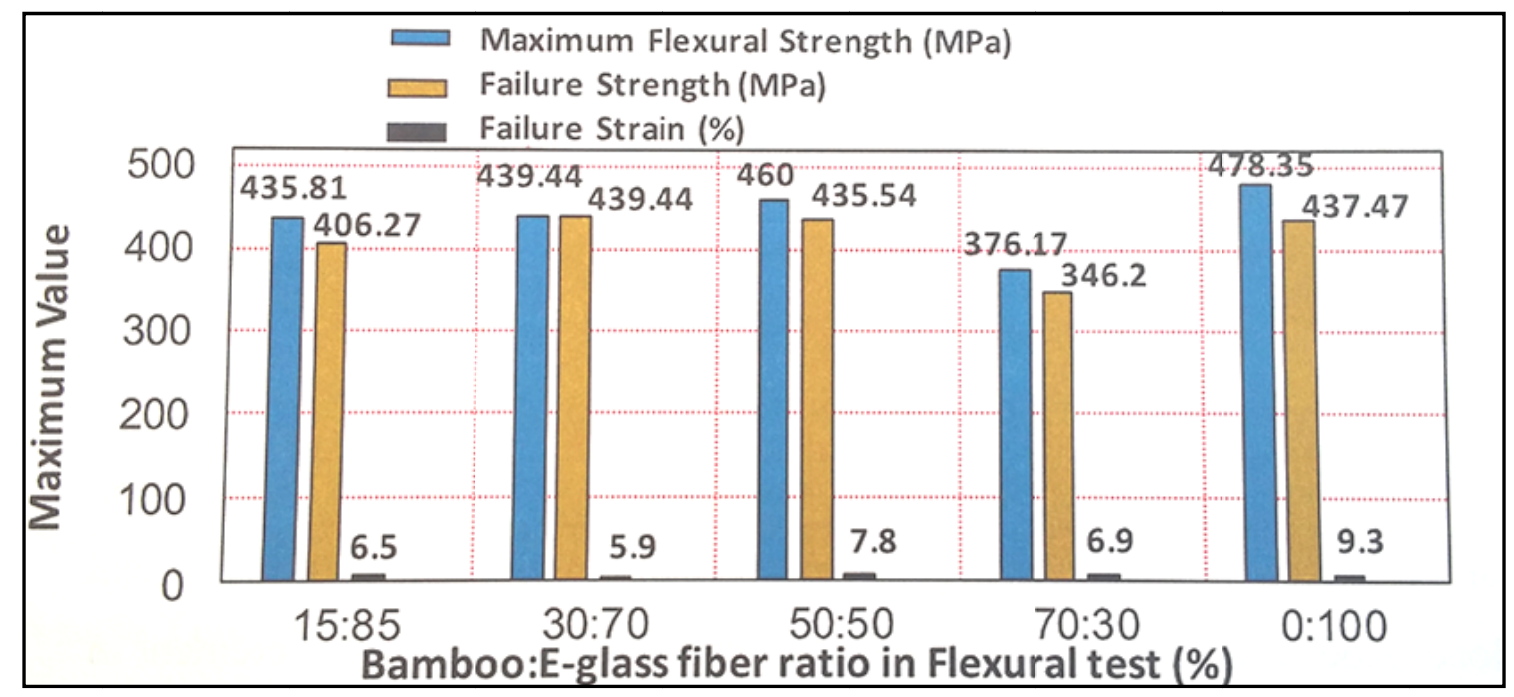

Fig. 8 Comparison of different bamboo/E-glass ratio flexural peak value. 


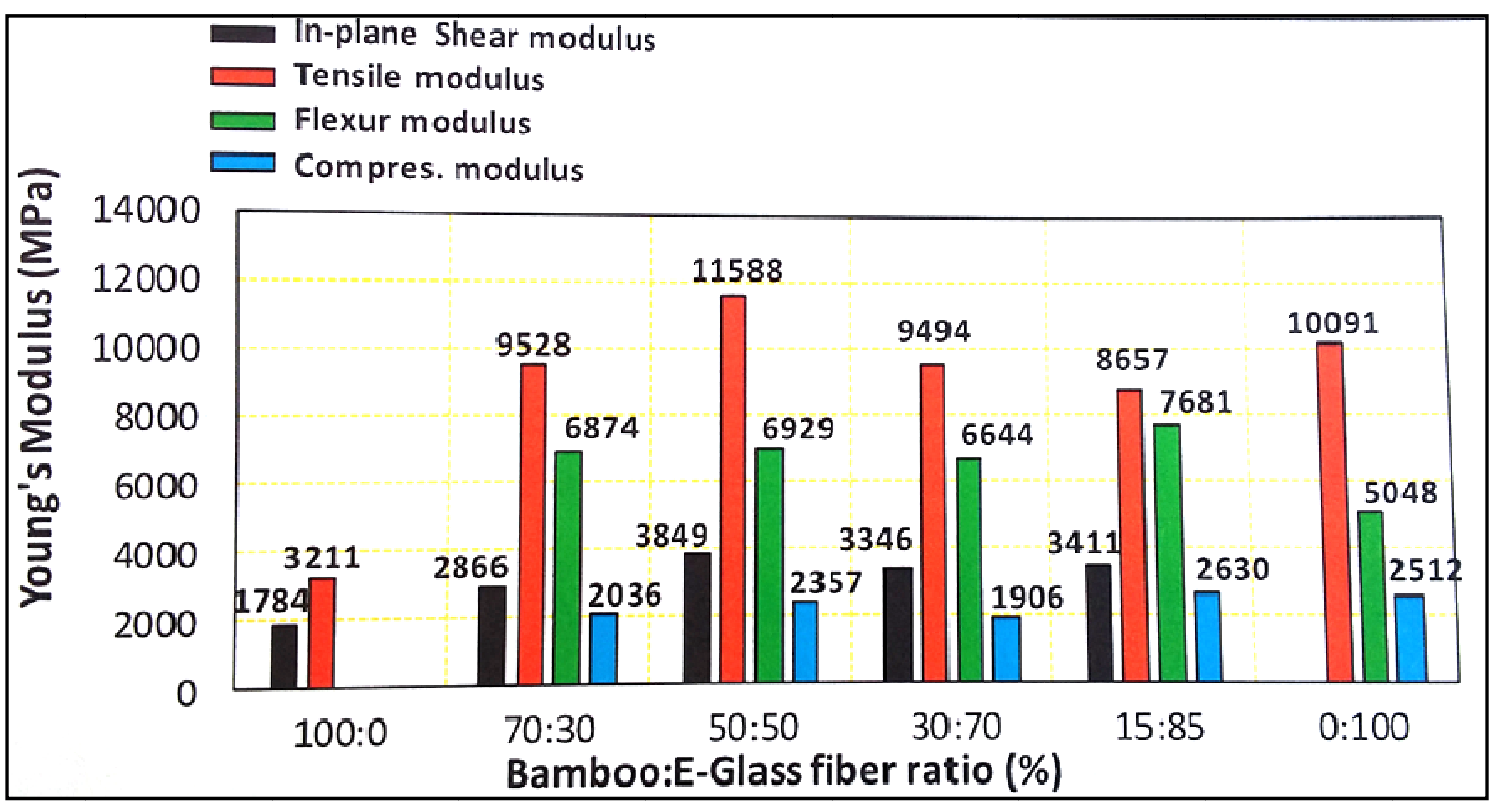

Fig. 9 Comparison of Young's Modulus for different fiber ratio.
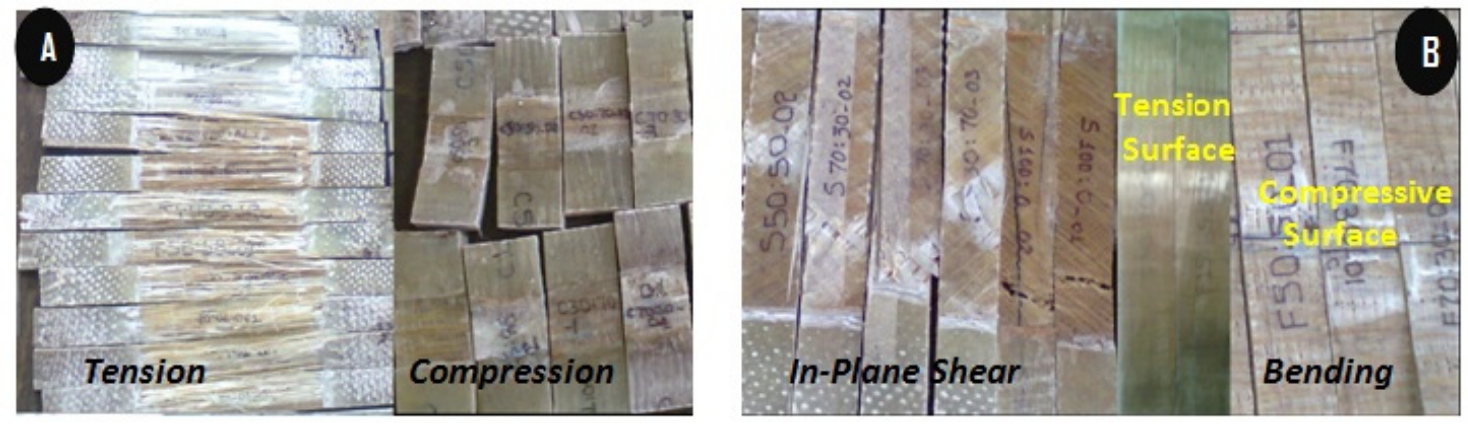

Fig. 10 (a) Intact coupon under tension and compression loading and (b) intact coupon under shear and bending load.

Table 1 Mode of failures under different loading conditions.

\begin{tabular}{lll}
\hline Loading condition & ASTM standards & Mode of failures identified in terms of codes \\
\hline Tensile & D3039 & XGM, LGM \\
In-plane shear & D3518/D3039 & AGM, DGM, LGM \\
Compressive & D3410 & AGM, BGM, TAT \\
Flexural & D790 & BBB, CBT, MUV, TAM \\
\hline
\end{tabular}

enhancing the growth of damaged area. The culmination of this last event is the complete loss of stiffness of specimens.

In the case of in-plane shearing test, most of the specimens failed by lateral failure type, in the middle of gage area; and only a few specimen's failure by edge delamination. In the case of flexural test, bending failure on the tension surface of specimens was due to matrix and fiber breakage while on the compressive surface was due to buckling of specimens.

\section{Conclusions}

The performance of bamboo and E-glass reinforced hybrid composite (BEGRC) was investigated based on tensile, compressive, in-plane shear and flexural tests. First, manual method of bamboo fiber extraction from Ethiopian highland bamboo species "Yushania Alpina" was undertaken and a $5 \% \mathrm{NaOH}$ was used for further lignin and hemicelluslose removal from fiber. Second, different mechanical properties of BEGRC 
were determined from different bamboo to E-glass fiber percentage of $45 \%$ total fiber volume. Thus, the following results are obtained:

The tensile, compressive, shear and flexural properties of BEGRC composites depends fundamentally on the amount layers in a laminate, angle and orientation of lamian and bamboo to E-glass fiber percentage presences in the composite.

High modulus of elasticity and compressive properties are obtained from bamboo to E-glass reinforced fiber ration of $50: 50$.

For a selected bamboo species, a three years old of extracted bamboo fiber is good enough to use as reinforced in structural fibers.

\section{References}

[1] Lugt, P., Dobbelsteen, A. A. J. F. and Janssen, J. J. A. 2005. "An Environmental, Economic and Practical Assessment of Bamboo." Accessed Oct. 16, 2008. http//www.bamboocraft.net.

[2] Abdul Khalil, H. P. S., Bhat, I. U. H., Jawaid, M., Zaidon, A., Hermawan, D. and Hadi, Y. S. 2012. "Bamboo Fiber Reinforced Bio Composites: A Review." Materials and Design 42: 353-68.

[3] Giovanni Belingardi, Ermias Gebrekidan Koricho, 'developing composite engine support sub-frame to achieve lightweight vehicles', 16th International Conference on Composite Structures ICCS 16, 2011
Porto.

[4] Koricho, E. G. 2012. "Implementation of Composite and Plastics Materials for Vehicle Light Weight.” Ph.D. thesis, Poly Technic University of Turin, 44-74.

[5] Durai Prabhakaran, R. T. 2012. "Future Materials for Wind Turbine Blades - A Critical Review." In Proceedings of International Conference on Wind Energy: Materials, Engineering and Policies (WEMEP-2012), Birla Institute of Technology and Science, Pilani-Hyderabad Campus, Hyderabad (India), November 22-23 (In CD).

[6] Lugt, P., Dobbelsteen, A. A. J. F. and Janssen, J. J. A. "An Environmental, Economic and Practical Assessment of Bamboo." Accessed Oct. 16, 2008. http//www.bamboocraft.net.

[7] Raghavendra Rao, H., Varada Rajulu, A., Ramachandra Reddy, G. and Reddy, K. H. 2010. "Flexural and Compressive Properties of Bamboo and Glass Fiber-Reinforced Epoxy Hybrid Composites." Journal of Reinforced Plastics and Composites 29: 1446.

[8] Wong, K. J., Yousif, B. F. and Low, K. O. 2010. "The Effects of Alkali Treatment on the Interfacial Adhesion of Bamboo Fibres." In Proceedings of the Institution of Mechanical Engineers, Journal of Materials, Design and Applications, 224 (3): 139-48.

[9] Gay, D., Hoa, S. V. and Tsai, S. W. 2003. "Composite Materials: Design and Applications." CRC Press LLC, Florida.

[10] Adjemian, F. and Evesque, P. 2004. "Experimental Study of Stick-Slip Behavior." International Journal for Numerical and Analytical Methods in Geomechanics 28: 501-30. 